\title{
REVIEW
}

\section{Physical examination of the patellofemoral joint}

\section{EXERCISE IS MEDICINE}

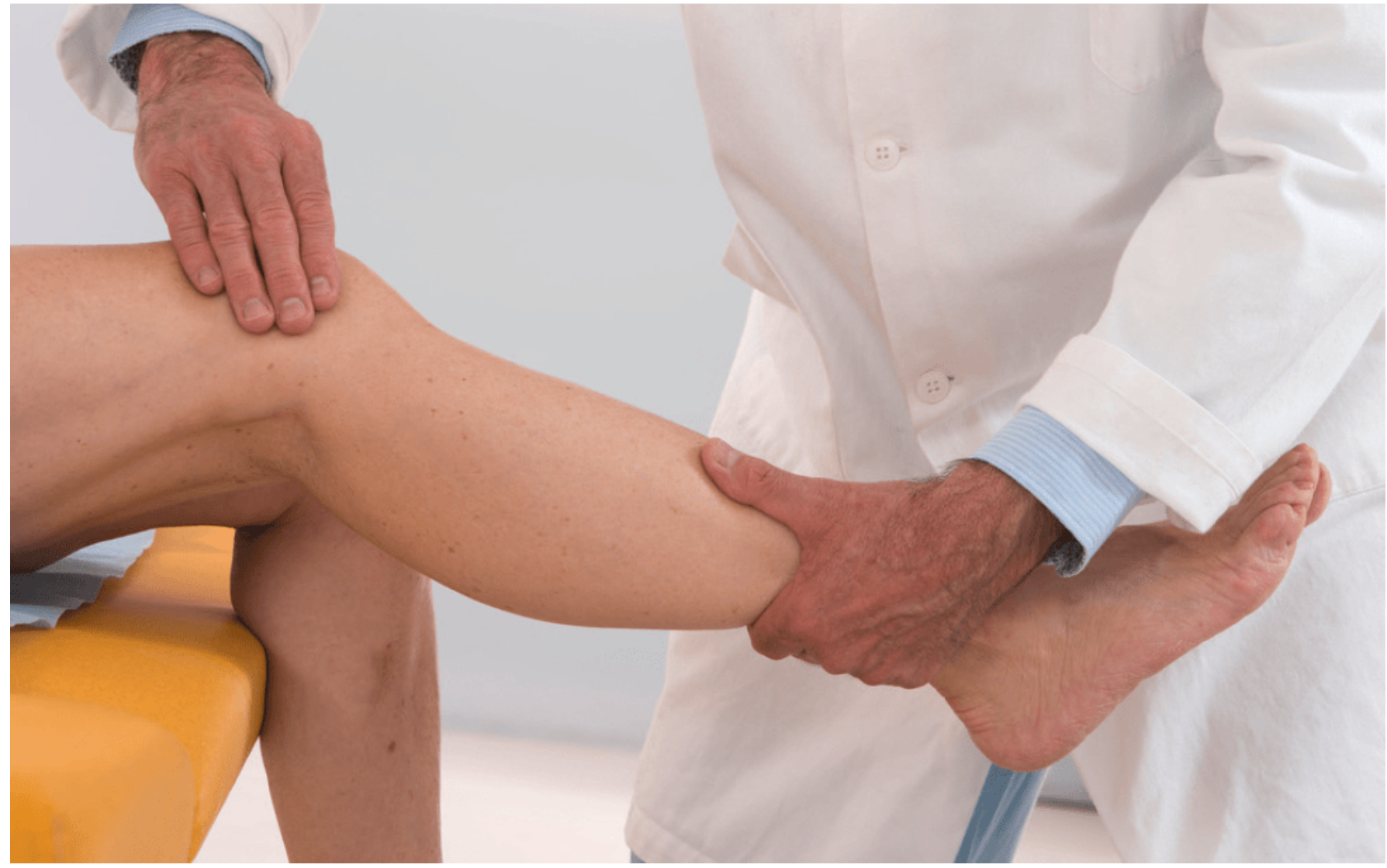

Furrer $\mathbf{P R}^{1}$, Laux $\mathrm{CJ}^{1,2}$, Fucentese $\mathbf{S F}^{1}$, Tscholl $\mathbf{P M}^{2}$

${ }^{1}$ Department of Orthopaedics, Balgrist University Hospital, University of Zurich

${ }^{2} \square$ Centre de médecine de l'appareil locomoteur et du sport et Swiss Olympic Medical Center Cressy Santé, Service de chirurgie orthopédique et traumatologie de l'appareil moteur, Hôpitaux Universitaires de Genève

\footnotetext{
Abstract

Patients with a patellofemoral pain are either in an acute state after a patellofemoral dislocation or are suffering from a chronic anterior knee pain (AKP), whereas AKP might be accompanied by patellar instability without dislocation. Whereas the acute state after a dislocation is mostly clear and its examination limited, the examination of a AKP is much more complex. A profound knowledge of the anatomy, the painful structures and patellofemoral biomechanics is essential in order to find the
} 
underlying pathology within the heterogeneous and diverse etiologies. Furthermore, a meticulous and precise examination is key to find the adequate treatment for AKP.

\section{Zusammenfassung}

Patienten mit patellofemoralen Schmerzen befinden sich entweder in einer akuten Phase nach PatellaLuxation oder leiden an einem chronischen vorderen Knieschmerz, welcher mit einem PatellaMaltracking verbunden sein kann. Wobei die Situation nach einer Dislokation meist klar und die Untersuchung aufgrund von starken Schmerzen limitiert ist, ist die Untersuchung bei chronischem vorderen Knieschmerz viel komplexer. Dies ist wichtig, um die zu Grunde liegende Pathologie zu diagnostizieren und zu verstehen, da die Ätiologie von chronischen vorderen Knieschmerzen sehr heterogen und vielfältig ist. Aus diesem Grund ist eine detaillierte Untersuchung auch der Schlüssel zur Einleitung einer adäquaten Patientenbehandlung.

\section{Introduction}

Patellofemoral disorders are the one of the most frequent exercise related complains in adolescents and young adults, and will affect one out of four athletes during their career. [1] The patient's history and clinical examination are key to detect the painful and deficient structures, the associated anatomical risk factors and functional deficits to make the correct diagnosis and decide on the ideal treatment. There are two major symptoms being presented:

1) Patellar dislocation (PD, acute or recurrent)

2) AKP (with or without patellar instability)

Primary PD is a mechanical event with a usually straight-forward patient history. Recurrent PD is more complex and often characterized by moderate to severe patellar maltracking. In general, recurrent PD has a major structural component with or without an associated functional deficit. AKP has always an important functional deficit, and can be associated with a morphological anomalies. Important to note, that maltracking as such might be physiological and often asymptomatic, it might only predispose potential patellofemoral disorders.

\section{Patient's history}

We differentiate between early posttraumatic situations following a PD and a rather chronic patellofemoral condition with predominant AKP.

\section{Early posttraumatic history}

After a primary PD, patients most often experience anxiety and severe knee pain, unlike patients with recurrent instability. It is important to ask the patient about the exact trauma mechanism of the most recent and previous patellar dislocations, whether it was a direct blow to the medial side of the patella or only a pivoting move. [2,3]

The mechanism in non-traumatic or non-contact injuries might resemble an anterior cruciate ligament 
(ACL) injury. In some cases, the patients might remember a snapping or cracking sensation. [4] Sometimes it is difficult to judge at all whether a dislocation has occurred or whether there is another underlying cause for the pain, as the patella is most often spontaneously reduced on arrival at the hospital. To diagnose PD, the patella must be seen dislocated by the patient or a person on site. Only the patient's suspicion of a dislocation might by misleading and inaccurate. In these situations, radiological imaging is more reliable and decisive.

\section{Systematic patellofemoral history/Anterior knee pain (AKP)}

AKP has a wide range of underlying pathologies and it may or may not be associated with patellar maltracking or a previous PD, yet it is important to ask specifically for these pathologies and to assess them clinically. [5,6]

Ask the patient in detail about the pain, its location, its quality, whether being dull or sharp and the extent of the pain, the time of onset and the changes of the pain over time. Not infrequently a combination of problems is seen or one leading to another. For example a trauma leading to functional malalignement and structural can lead to AKP, most probably more frequently with one or two morphological risk factors, such as trochlear dysplasia and patella alta. Hereditary malalignments and early onset are essential to investigate on. [3] Also ask about previous operations, which can lead to malalignment or patella baja due to infrapatellar scarring.

Furthermore, pain triggering factors need to be enquired. [7] Postural AKP while in a flexed position for a longer period of time and having to extend the knee from time to time for pain relief, is suspicious for a pathology to the extensor mechanism and not to the femorotibial joint. Pain while jumping, running or ascending and descending steps may indicate a tendinopathy amongst others. Ask for "giving-way" sensations. [2,4,5] This is a sudden feeling of subjective instability of the knee which can be associated with pain. Painless "giving-way" can be associated with a transient patellar malposition or subluxation, a trapped synovial plica or an unstable cartilage flap [8,9], or any other ligamenouts or meniscal instability of the femorotibial joint. Rotational movements leading to "giving-way" is more common with ACL insufficiency or meniscal injuries than with patellofemoral issues. Therefore, investigating AKP always requires the understanding of potential underlying femorotibial pathologies.

Evaluating the adjacent joints is essential to exclude radiating pain, and the biomechanical context of AKP.

\section{Physical examination}

The authors highly stress a complete and systematic clinical examination in order to find the underlying pathologies. Set up an ideal examination environment and ask the patient to remove shoes, socks and pants. [5]

\section{Early posttraumatic assessment}

Due to severe pain, a detailed examination is hardly ever possible.

Inspection: The knee is often held in a slightly flexed position due to fear of another dislocation when completely extending the knee. The flexed position will guide the patella into the trochlear groove, which is more comfortable for the patient. Flexion of more than $45^{\circ}$ is rarely possible, due to soft-tissue injury to the vastus medialis muscle (VM) and the medial patellofemoral ligament (MPFL). 
Palpation: Evaluate for swelling or effusion. Acute PD may be accompanied by an effusion which indicates capsuloligamentous injury, hence arthrotomy. Recurrent or chronic PD can occur without joint effusion. In the early posttraumatic state, the entire knee might be painful due to the injured medial and lateral retinacular system covering the entire knee. If possible, the patient should locate the exact pain and thereby provide better information on injured structures. A damage to the MPFL is very likely with rupture at the femoral or patellar insertion. Pain to the distal VM is common since it serves as insertion site for the MPFL. [10]

Function: A detailed functional testing is hardly ever possible after acute patellar dislocation. In this case, examine the contralateral lower limb to estimate the patient's risk profile. Hence, clinical examination is not helpful to determine indication for early surgical treatment for PD.

\section{Systematic clinical examination of patellofemoral disorders}

The detailed patellofemoral examination permits to evaluate patellofemoral anatomy, its biomechanical behavior, and includes the examination of the entire limb at rest but also in function.

Inspection: While the patient is standing the leg axis and the patella location should be inspected carefully. A genu valgum, excessive femoral antetorsion and consecutive tibial external rotation are independent risk factors for patellar instability. Latter can be seen as with an explicitly medial orientation of the patella, the so called a "squinting patella". [5,11] (Figure 1) The Q-angle represents an angle from the antero-superior iliac spine to the center of the patella to the tip of the tibial tubercle, and quantifies the lateral vector force of the patella. An angle above $15^{\circ}$ is said to be increased. Since the Q-angle in patients with lateral patellar subluxation is falsely normal, the tubercle-sulcus angle in $90^{\circ}$ of knee flexion has become more routinely used. This is the angle between a line from the tibial tubercle to the center of the patella (thought to be the trochlear sulcus) and the transepicondylar line, normally $90^{\circ}$. [12] (Figure 2) Next check the patellar height. A patella baja is more prone to AKP due to its decreased mobility, a patella alta is a risk factor for instability due to its associated hypermobility as it exits the bony restraints of the trochlear groove in extension [13] and to AKP. [14]

Palpation: Palpate the crucial patellofemoral landmarks. (Figure 3) Tenderness to the distal patellar tip, may indicate a patellar tendinopathy (Jumper's knee), usually located more medially than laterally. Tenderness to the lateral-distal patellar tip is more often seen in the superolateral Hoffa impingement syndrome, associated with patella alta. Also palpate the lateral retinaculum insertion to the patella. It is often painful in patellar maltracking, or after blunt trauma, associated with a hypomobile and tilted patella, with or without a retracted iliotibial tractus. [15] In $90^{\circ}$ flexion the pes anserinus needs specific attention, since the aponeurosis of the sartorius muscle is in continuation with the entire parapatellar medial retinaculum and the superficial sheath of the VM aponeurosis, which often is painful in AKP or following PD. A palpable gap to the VM and a more cranial insertion may be palpated as a sign of a former PD.

Function: (Table 1) Get an overview of the joint mobility and its stability. Passively measure the range of motion (ROM) in the femorotibial joint. Normal ROM is around $140^{\circ}$ of flexion and $5-10^{\circ}$ of extension and should be compared to the contralateral side. Check for flexion contracture or extension tightness, which has a wide variety of underlying pathologies, and can influence the biomechanics of the patellofemoral joint. The medio-lateral translation of the patella is tested in full extension and should not be more than $50 \%$ of the patellar width. Excessive lateral shift might be seen after PD and insufficient scaring of the 
MPFL. Excessive medial shift may be iatrogenic following a lateral release. [16] Medio-lateral translation above $30^{\circ}$ flexion of more than 1 quarter is highly associated with trochlear dysplasia.

\begin{tabular}{|c|c|c|c|}
\hline & Explanation & Physiologic & Pathologic \\
\hline \multicolumn{4}{|l|}{$\begin{array}{l}\text { Passive } \\
\text { Examination }\end{array}$} \\
\hline $\begin{array}{l}\text { Patella } \\
\text { medio-lateral } \\
\text { translation }\end{array}$ & $\begin{array}{l}\text { Knee in Extension, hold the patella } \\
\text { with two fingers, shift it horizontally } \\
\text { medial and lateral }\end{array}$ & $\begin{array}{l}<50 \% \text { of patella width trans- } \\
\text { lation to either side }\end{array}$ & $\begin{array}{l}>50 \% \text { of patella width trans- } \\
\text { lation to either side }\end{array}$ \\
\hline Patella tilt & $\begin{array}{l}\text { Knee in } 0^{\circ} \text { flexion, hold the patella } \\
\text { with two fingers and try to flip it } \\
\text { laterally }\end{array}$ & $\begin{array}{l}\text { Tilt above horizontal plane } \\
\text { possible (positive tilt) }\end{array}$ & $\begin{array}{l}\text { Tilt to horizontal plane not } \\
\text { possible (negative tilt) or } \\
\text { excessive positive tilt }\end{array}$ \\
\hline Apprehension & $\begin{array}{l}\text { Knee in } 20^{\circ} \text { flexion, try to push the } \\
\text { patella lateral or medial as to dislo- } \\
\text { cate }\end{array}$ & No fear, no pain & Fear, resistance or pain \\
\hline $\begin{array}{l}\text { Pressure to } \\
\text { femoro- } \\
\text { patellar joint }\end{array}$ & $\begin{array}{l}\text { Gently move the patella on the femo- } \\
\text { ral trochlea in every direction and } \\
\text { apply minimal pressure }\end{array}$ & $\begin{array}{l}\text { No pain, no catching. } \\
\text { no crepitation }\end{array}$ & $\begin{array}{l}\text { Pain, crepitation, catching, } \\
\text { apprehension }\end{array}$ \\
\hline \multicolumn{4}{|l|}{$\begin{array}{l}\text { Active } \\
\text { Examination }\end{array}$} \\
\hline $\begin{array}{l}\text { Functional } \\
\text { lateralization } \\
\text { test }\end{array}$ & $\begin{array}{l}\text { The leg is in full extension, ask the } \\
\text { patient to contract the quadriceps }\end{array}$ & $\begin{array}{l}\text { Patella is proximalised but } \\
\text { stays aligned }\end{array}$ & $\begin{array}{l}\text { No patellar proximalisation } \\
\text { linfrapatellar scarring. } \\
\text { patella inferal } \\
\text { Increased proximalisation, } \\
\text { lateralization and tilting }\end{array}$ \\
\hline$J$-sign & $\begin{array}{l}\text { The patient is sitting and performs } \\
\text { and open chain knee extension } \\
\text { movement knee up to full extension }\end{array}$ & Patellar tracking aligned & $\begin{array}{l}\text { Patella shifts lateral at full } \\
\text { extension }\end{array}$ \\
\hline
\end{tabular}

Table 1: Overview of the function testing on the patellofemoral joint. 


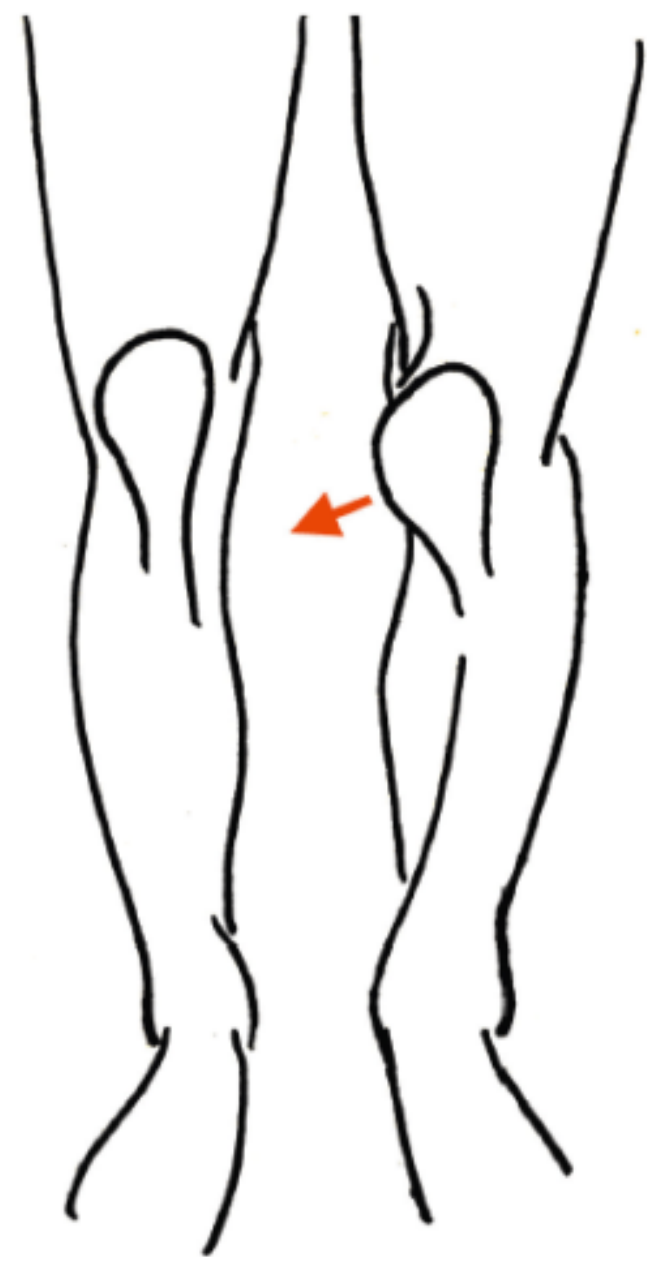

Figure 1: Squinting patella. An explicit medial orientation of the patella due to femoral malrotation. Seen on this patient's left knee. 


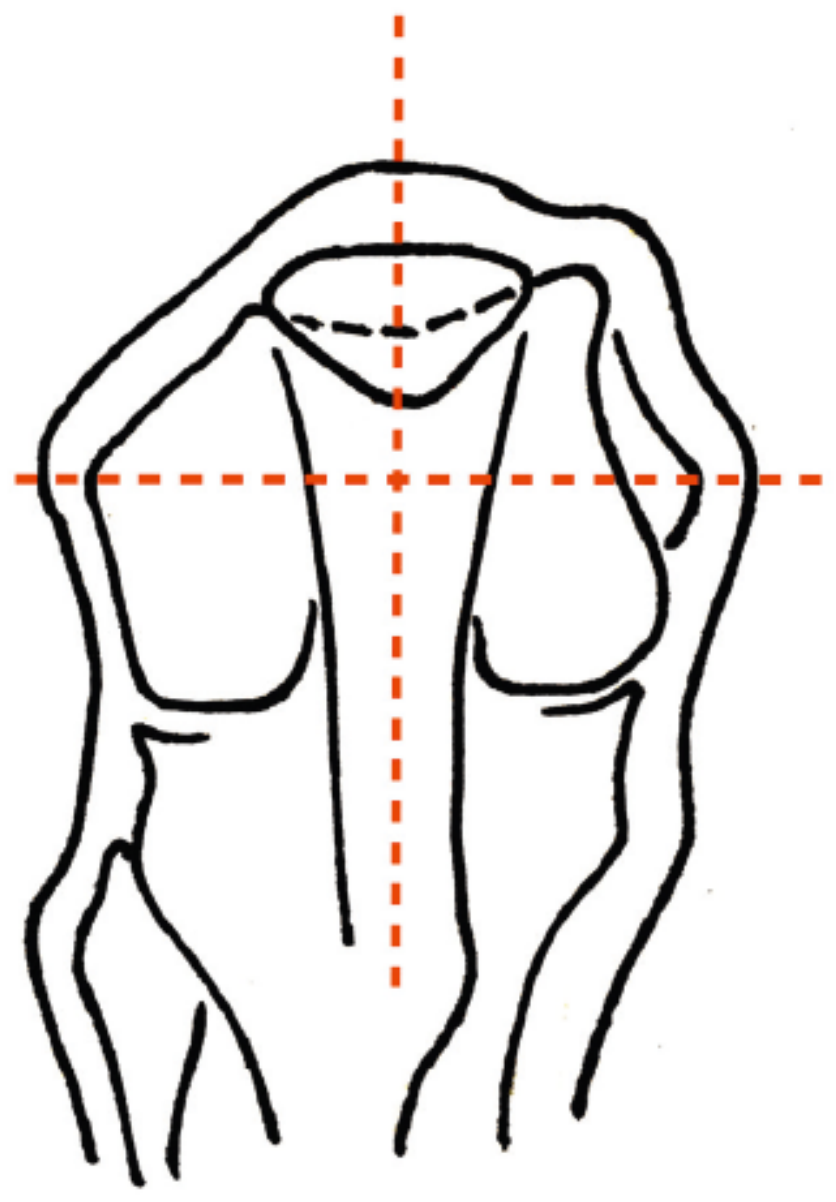

Figure 2: Tubercle-sulcus angle. This is the angle between the line from the tibial tubercle to the trochlear sulcus and the line from the medial to the lateral condyl.

Normally the patella is centered in the middle of the sulcus and the angle is $90^{\circ}$. If the angle is not $90^{\circ}$ it indicates a lateralization of the patella. 

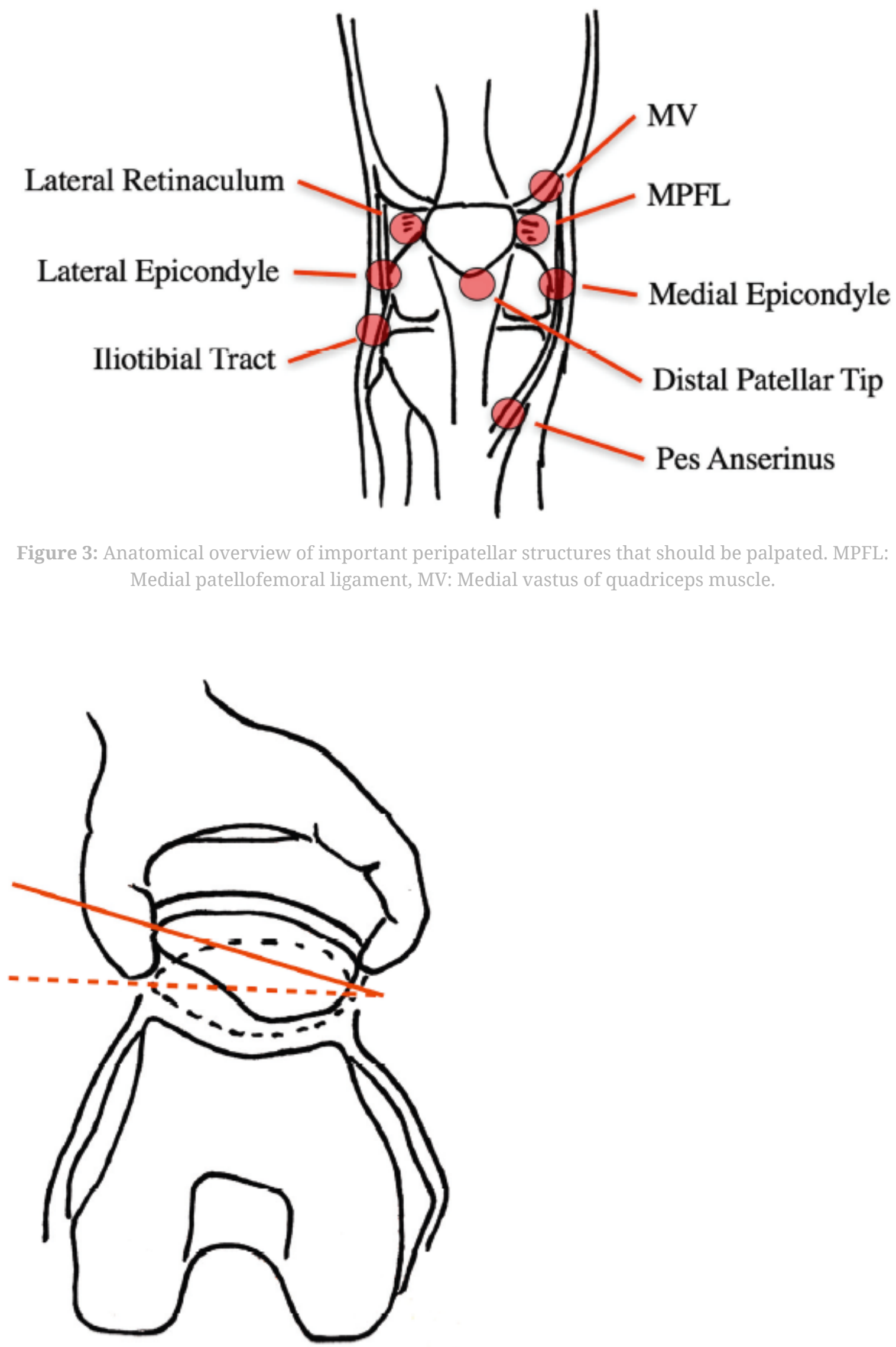
Figure 4: Patellar tilt. In relaxed state the patella is tilted up on the lateral side. Normally it can be tilted above the horizontal plane. It is an indicator for the tightness of the lateral retinaculum.

The patellar tilt is a parameter for tightness of the lateral retinaculum. (Figure 4) The knee relaxed in $0^{\circ}$ flexion, try to flip the lateral patella upwards. A normal patella can be tilted upwards above horizontal. Limited upward (negative) tilt indicates lateral retinacular tightness and correlates to radiologic patella lateralization. [8,17-19] Also check the cranio-caudal mobility of the patella, that can be decreased postoperatively in Hoffa and parapatellar retinacular scarring. It limits the femorotibial range of motion and increases the contact pressure on the patellofemoral joint leading to AKP.

Symptomatic cartilage injury can be found by gently applying pressure to the patella, and by gliding it over the femoral trochlea in full extension. Locking, crepitation and pain can be noticed or mentioned by the patient. $[18,20]$ For the patellar apprehension test, the patient is in supine position and the knee flexed in $20-30^{\circ}$. The patella is pushed laterally and the test is positive when the patient is feeling discomfort, pain or avoidance with quadriceps activation which pulls the patella back in place. [17,20-22] This test is also valid when pushing the patella medially for a medial instability, although it may be misleading and rather indicative for a lateral subluxation of the patella and the fear of the relocation. Note, that medial instability is often iatrogenic after a lateral release of the patella or associated with increased femoral antetorsion. [16] Examination of the hip, back and pelvis may give information about a torsional malalignment if internal rotation exceeds external rotation of the hip or causes of radiating pain to the anterior knee. [23] The general laxity of the patients should be checked using the Beighton score. A joint hypermobility is defined $\geq 4$ points. (Table 2) $[5,24]$

\begin{tabular}{|c|c|}
\hline Beighton score & Points \\
\hline $\begin{array}{l}\text { Is the patient able to rest with the palms flat on the floor during } \\
\text { flexion of the trunk with fully extended legs }\end{array}$ & Maximal 1 point \\
\hline Is there hyperextension of the small fingers $>90^{\circ}$ & Maximal 2 points \\
\hline passive apposition of the thumb to the volar aspect of the forearm & Maximal 2 points \\
\hline hyperextension of the elbows $>10^{\circ}$ & Maximal 2 points \\
\hline hyperextension of the knee $>10^{\circ}$ & Maximal 2 points \\
\hline
\end{tabular}

Table 2: Beighton score, one point is given for every possible move. Examination on the extremities are done for either side.

Active functional testing is started in full extension with an active patellar proximalisation through quadriceps contraction. This requires an intact quadriceps muscle, a sufficient strength, full extension, no or only slight effusion and no clinically relevant infrapatellar scarring. An increased patellar lateralization during this maneuver may be seen with pathologic structural anatomies, or simply as asymptomatic, nonpathological finding. Underlying problems may be a patella alta, an insufficient MPFL scaring, a trochlea dysplasia, or a short lateral trochlear facet leading all to a decreased engagement of the patella into the femoral trochlea in full extension. [13] In an open chain examination with the patient actively extending 
the knee from a flexed position, a lateralization of the patella may be seen when approaching extension. When again flexing the knee, the patella jumps back medially in place as soon as the bony stabilization of the trochlear grove is effective. This is called the J-sign and indicates a patellofemoral maltracking. [25] (Figure 5)

Examination of muscle strength around hip and knee is crucial. Hip abductor weakness may lead to insufficient control of internal rotation of the femur and therefore is a primary cause of patellofemoral malalignment. (18) A flexion contracture in the hip is also an individual risk factor to AKP. [21] Closed chain examinations such as single-leg or bipodal squats will give a rough appreciation of functional alignment and lower limb coordination. [22,26,27]

Careful inspection of the gait is important. Limping may be seen when the patient is in pain, a muscle contracture or a muscle atrophy is present. [5] Malrotations are mostly not painful however showing an abnormal gait with increased kneeing-in or outwards rotation of the foot. An abnormal resting position of the foot may be a sign of torsional abnormalities of the lower extremity, or a protective mechanism to prevent patellofemoral instability.
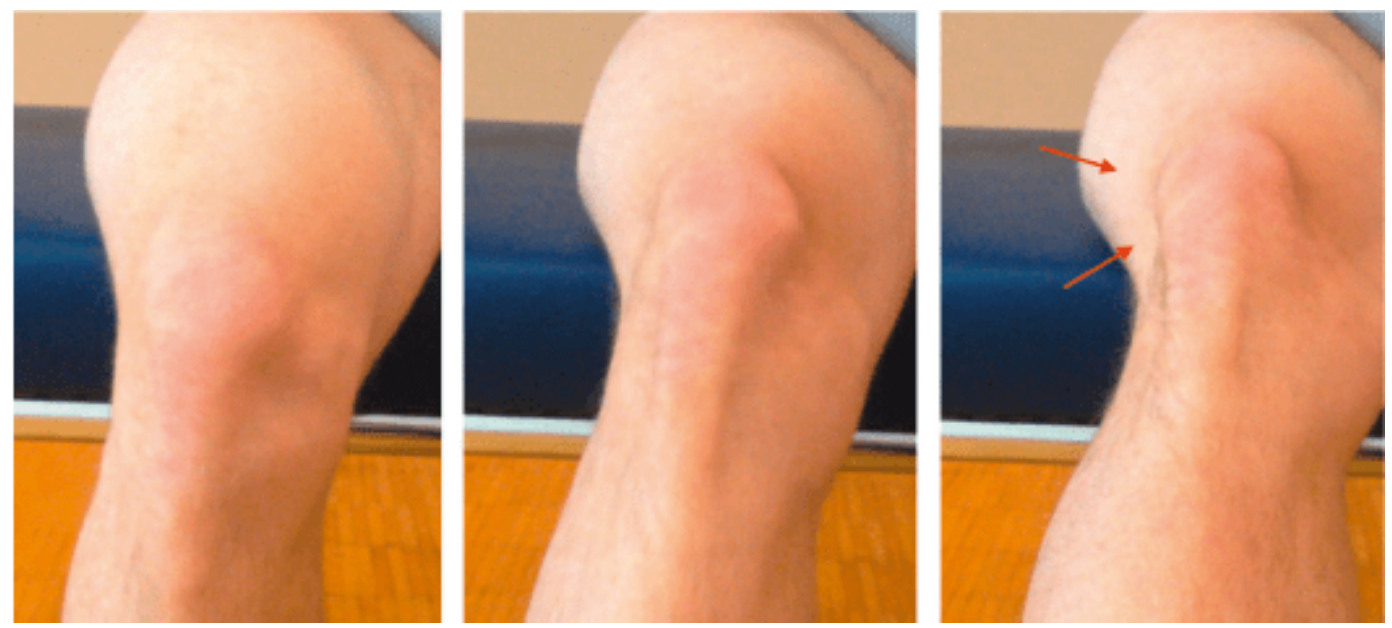

Figure 5: J-sign. The knee is actively extended. Towards the end of the extension the patella slides laterally out of the trochlear stabilizat

\section{Conclusion}

This article provides a comprehensive overview of the clinical assessment of the patellofemoral joint. The treating physician needs to be aware of the complex and often multifactorial etiology of patellofemoral instability. Whereas the assessment of an acute patellofemoral dislocation is rather straight forward, the chronic situation requires a more sophisticated clinical approach, with consideration of soft tissue and bony restraints, adjacent joints, leg axis and torsional alignment.

\section{Practical implication}

- A traumatic patellofemoral dislocation is rather straight forward, whereas the chronic AKP with or without instability is complex situation.

- The conclusive examination of the patellofemoral joint is important in order to detect the underlying 
causes.

- AKP might have an isolated structural or isolated functional pathology as a cause, more often it is a combination.

\section{Acknowledgements, conflict of interest and funding}

Authors must state all possible conflicts of interest in the manuscript, including financial, institutional and other relationships that might lead to a conflict of interest. If there is no conflict of interest, this should be stated as none declared. All sources of funding must be acknowledged at the end of the manuscript.

\section{Corresponding author}

Pascal Raffael Furrer

Forchstrasse 340

8008 Zurich

Tel: 0443865765

Email: pascal_furrer@icloud.com

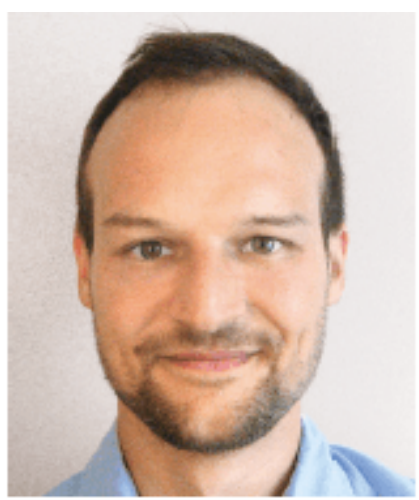

\section{References}

1. Witvrouw E, Lysens R, Bellemans J, Cambier D, Vanderstraeten G. Intrinsic risk factors for the development of anterior knee pain in an athletic population. A two-year prospective study. Am J Sports Med. 2000;28(4):480-9.

2. Clark D, Metcalfe A, Wogan C, Mandalia V, Eldridge J. Adolescent patellar instability: current concepts review. Bone Joint J. 2017;99-B(2):159-70.

3. Fithian DC, Paxton EW, Stone ML, Silva P, Davis DK, Elias DA, et al. Epidemiology and natural history of acute patellar dislocation. Am J Sports Med. 2004;32(5):1114-21.

4. Rossi R, Dettoni F, Bruzzone M, Cottino U, D’Elicio DG, Bonasia DE. Clinical examination of the knee: know your tools for diagnosis of knee injuries. Sports Med Arthrosc Rehabil Ther Technol. 2011;3:25.

5. Lester JD, Watson JN, Hutchinson MR. Physical examination of the patellofemoral joint. Clin Sports Med. 2014;33(3):403-12.

6. Donell s. Patellofemoral dysfunction - Extensor mechanism malalignment. Elsevier; 2006.

7. Cook C, Hegedus E, Hawkins R, Scovell F, Wyland D. Diagnostic accuracy and association to disability of clinical test findings associated with patellofemoral pain syndrome. Physiother Can. 2010;62(1):17-24.

8. Laurin CA, Lévesque HP, Dussault R, Labelle H, Peides JP. The abnormal lateral patellofemoral angle: a diagnostic roentgenographic sign of recurrent patellar subluxation. J Bone Joint Surg Am. 1978;60(1):55-60.

9. Grelsamer RP. Patellar nomenclature: the Tower of Babel revisited. Clin Orthop Relat Res. 2005(436):60-5.

10. Desio SM, Burks RT, Bachus KN. Soft tissue restraints to lateral patellar translation in the human 
knee. Am J Sports Med. 1998;26(1):59-65.

11. Parikh S, Noyes FR. Patellofemoral disorders: role of computed tomography and magnetic resonance imaging in defining abnormal rotational lower limb alignment. Sports Health. 2011;3(2):158-69.

12. Kolowich PA, Paulos LE, Rosenberg TD, Farnsworth S. Lateral release of the patella: indications and contraindications. Am J Sports Med. 1990;18(4):359-65.

13. Biedert RM, Tscholl PM. Patella Alta: A Comprehensive Review of Current Knowledge. Am J Orthop (Belle Mead NJ). 2017;46(6):290-300.

14. Tscholl PM, Biedert RM, Wanivenhaus F, Fucentese SF. Patellar tendinopathy with intratendinous alteration on MRI may be related to patellofemoral dysplasia. Scand J Med Sci Sports. 2018;28(4):1443-50.

15. Sanchis-Alfonso V, Roselló-Sastre E, Revert F. Neural growth factor expression in the lateral retinaculum in painful patellofemoral malalignment. Acta Orthop Scand. 2001;72(2):146-9.

16. Hughston JC, Deese M. Medial subluxation of the patella as a complication of lateral retinacular release. Am J Sports Med. 1988;16(4):383-8.

17. Smith TO, Davies L, O'Driscoll ML, Donell ST. An evaluation of the clinical tests and outcome measures used to assess patellar instability. Knee. 2008;15(4):255-62.

18. Fredericson M, Yoon K. Physical examination and patellofemoral pain syndrome. Am J Phys Med Rehabil. 2006;85(3):234-43.

19. Grelsamer RP, Weinstein $\mathrm{CH}$, Gould J, Dubey A. Patellar tilt: the physical examination correlates with MR imaging. Knee. 2008;15(1):3-8.

20. Malanga GA, Andrus S, Nadler SF, McLean J. Physical examination of the knee: a review of the original test description and scientific validity of common orthopedic tests. Arch Phys Med Rehabil. 2003;84(4):592-603.

21. Sanchis-Alfonso V. Evaluation of the Patient with Anterior Knee Pain and Patellar Instability. Montesinos-Berry E, editor: Springer; 2011.

22. Nijs J, Van Geel C, Van der auwera C, Van de Velde B. Diagnostic value of five clinical tests in patellofemoral pain syndrome. Man Ther. 2006;11(1):69-77.

23. Lee TQ, Morris G, Csintalan RP. The influence of tibial and femoral rotation on patellofemoral contact area and pressure. J Orthop Sports Phys Ther. 2003;33(11):686-93.

24. Beighton P, Solomon L, Soskolne CL. Articular mobility in an African population. Ann Rheum Dis. 1973;32(5):413-8.

25. Sheehan FT, Derasari A, Fine KM, Brindle TJ, Alter KE. Q-angle and J-sign: indicative of maltracking subgroups in patellofemoral pain. Clin Orthop Relat Res. 2010;468(1):266-75.

26. Nunes GS, Stapait EL, Kirsten MH, de Noronha M, Santos GM. Clinical test for diagnosis of patellofemoral pain syndrome: Systematic review with meta-analysis. Phys Ther Sport. 2013;14(1):54-9.

27. Willy RW, Hoglund LT, Barton CJ, Bolgla LA, Scalzitti DA, Logerstedt DS, et al. Patellofemoral Pain. J Orthop Sports Phys Ther. 2019;49(9):CPG1-CPG95. 